\title{
A pharmacogenomic prospective randomized controlled trial of CYP2B6 polymorphisms and efavirenz dose adjustment among HIV-infected Thai patients: a pilot study
}

\author{
This article was published in the following Dove Press journal: \\ Pharmacogenomics and Personalized Medicine \\ 3 October 2015 \\ Number of times this article has been viewed
}

\section{Pansachee Damronglerd' Chonlaphat Sukasem ${ }^{2,4}$ Wilawan Thipmontree 3 Apichaya Puangpetch ${ }^{2,4}$ Sasisopin Kiertiburanakul' \\ 'Deparment of Medicine, ${ }^{2}$ Department of Pathology, Faculty of Medicine Ramathibodi Hospital, Mahidol University, Bangkok, ${ }^{3}$ Department of Medicine, Faculty of Medicine, Maharat Nakhon Ratchasima Hospital, Nakhon Ratchasima, ${ }^{4}$ Laboratory for Pharmacogenomics, Somdech Phra Debaratana Medical Center, Faculty of Medicine Ramathibodi Hospital, Mahidol University, Bangkok, Thailand}

Objective: We aimed at comparing clinical/immunological outcomes in human immunodeficiency virus (HIV)-infected patients who were treated with CYP2B6-guided and conventional efavirenz (EFV) therapy.

Methods: This study was a 24-week prospective randomized controlled trial. Eligible patients were HIV-infected adults yet to start antiretroviral therapy. Twenty-four HIV-infected patients were recruited and randomly assigned to genotype $C Y P 2 B 6$ polymorphism before ART initial dose. Patients with $C Y P 2 B 6^{*} 6 /{ }^{*} 6$ received $400 \mathrm{mg}$ EFV-based regimen and those with other genotypes received $600 \mathrm{mg}$ EFV-based therapy.

Results: For CYP2B6 polymorphism, 12 patients were extensive metabolizers, ten patients were intermediate metabolizers, and only two patients were poor metabolizers $(* 6 / * 6)$. The overall mean EFV plasma concentrations were similar in both groups. The mean drug concentrations (standard deviation) were $1.675(0.963), 1.445(0.778)$, and $1.899(0.808) \mu \mathrm{g} / \mathrm{mL}$ at week 4,12 , and 24 , respectively. The $C Y P 2 B 6 * 6 / * 6$ patient who received low dose of EFV had lower mean EFV level than those who received a normal dose, 1.916 versus $3.915 \mu \mathrm{g} / \mathrm{mL}(P<0.001)$, respectively. Seventy percent of the patients had neuropsychiatric adverse events, especially dizziness.

Discussion: There was a trend toward association of the $C Y P 2 B 6$ polymorphism and plasma EFV concentrations in this study. Reduced EFV dose should be considered in CYPB6 * $6 /{ }^{*} 6$ carrier to keep the drug concentration in therapeutic range.

Keywords: CYP2B6 polymorphism, efavirenz, prospective study, Thai, HIV-infected patient, pharmacogenetics

\section{Introduction}

Human immunodeficiency virus (HIV) infection is an important public health problem across the world. Combined antiretroviral therapy (ART) is the standard of care in HIVinfected patients, which enables them to live longer. However, with this regimen, patients will have to stay on medication for the rest of their life. In addition, antiretroviral drugs can have dangerous side effects in both long and short terms. The recommendation of ART guideline comprises two nucleoside reverse transcriptase inhibitors (NRTIs) and one nonnucleoside reverse transcriptase inhibitor (NNRTI) or protease inhibitor if the patient is intolerant to NNRTI. Efavirenz (EFV)-based regimen is recommended as the first-line regimen by many guidelines, eg, World Health Organization, ${ }^{1}$ European AIDS Clinical Society, ${ }^{2}$ and Thai national guidelines. ${ }^{3}$

EFV has many neuropsychiatric adverse side effects, such as light-headedness, dizziness, difficulty sleeping, and vivid and/or disturbing dreams. ${ }^{4-6}$ These side effects
Correspondence: Sasisopin Kiertiburanakul Deparment of Medicine, Faculty of Medicine Ramathibodi Hospital, Mahidol University, Bangkok 10400, Thailand Tel +6622010033

Fax +6622012232

Email sasisopin.kie@mahidol.ac.th 
occurred in approximately $50 \%$ of all patients and were relevant to the drug level in plasma. ${ }^{5,7-9}$ The normal requirement level of EFV is $1-4 \mu \mathrm{g} / \mathrm{mL}$, and the neuropsychiatric effects could be increasingly found if the EFV level was more than $4 \mu \mathrm{g} / \mathrm{mL} .{ }^{5}$ Nevertheless, the EFV level also had an impact on the success of the treatment. If the EFV level was in the therapeutic level, the more the number of patients with HIV RNA falling to undetectable levels. ${ }^{5,10}$

For the past few years, there have been many studies on pharmacogenetics and pharmacodynamics associated with therapeutic drug monitoring. The lower metabolizer enzymes and protein transporters seem to influence the pharmacokinetics of antiretroviral drugs, ultimately determining its efficacy and toxicity. ${ }^{11}$ They are widely used in pharmacogenetics and antiretroviral drugs, eg, $H L A-B * 5701$ with abacavir ${ }^{12}$ and cytochrome P450 (CYP) $2 B 6$ with nevirapine (NVP) and EFV. ${ }^{13,14}$ EFV needs hepatic $C Y P 2 B 6$ as the key component to metabolize and eliminate itself from the body. Genetic polymorphisms in $C Y P 2 B 6$, resulting from a nucleotide substitution at some positions, are associated with lower rate of EFV metabolism and lead to high exposure as well as a higher risk of neuropsychiatric adverse event, ${ }^{9,13,15,16}$ especially the homomutant variant: $C Y P 2 B 6 * 6 / * 6 .{ }^{16-18}$ These correlations led to suggestions to reduce the EFV dosage. The $C Y P 2 B 6^{*} 6$ carriers in the Japanese population who received EFV $600 \mathrm{mg}$ had a very high EFV concentration in plasma, and EFV was reduced from 600 to $200 \mathrm{mg}$ to remain in normal therapeutic range and minimize adverse neuropsychological events. ${ }^{19}$ In Thailand, the prevalence of $C Y P 2 B 6 * 6 / * 6$ was approximately $8 \% .{ }^{18}$ Patients with $C Y P 2 B 6 * 6 / * 6$ had very high plasma level of EFV (ranges: $5.85-13.47 \mu \mathrm{g} / \mathrm{mL}$ ). ${ }^{14,19-21}$ To our knowledge, there was no prospective trial comparing efficacy and safety of EFV dosage adjustment according to CYP2B6. Thus, we aimed at comparing the proportion of patients who had undetectable HIV RNA at 24 weeks after ART initiation among patients who received CYP2B6-guided EFV dose and who did not. The adverse neuropsychiatric events and EFV plasma concentration were evaluated. The prevalence of CYP2B6 and effectiveness of performing CYP2B6 screening were other aims to be determined.

\section{Methods}

\section{Study population}

This study was a 24-week prospective randomized controlled trial. Patients were recruited from two hospitals in Thailand: Ramathibodi Hospital and Maharat Nakhon Ratchasima Hospital, between April 2013 and April 2014. The study protocol was approved by the Ethical Clearance Committee on Human Rights Related Research Involving Human Subjects, Faculty of Medicine Ramathibodi Hospital, Mahidol University on May 22, 2013 (number MURA 2013/318). Written informed consent was obtained from each patient. Eligible patients at screening were HIV-infected adults older than 18 years with no previous exposure to ART. Patients were excluded if they were pregnant or breast-feeding; were receiving $\operatorname{drug}(\mathrm{s})$ that might have an interaction with EFV, eg, rifampicin, fluconazole, ergot alkaloid, midazolam, triazolam, ritonavir, carbamazepine, phenytoin, phenobarbitone, or St John's Wort; were having active opportunistic infection, eg, tuberculosis, cryptococcosis, histoplasmosis, or penicillosis; and had hepatic dysfunction as indicated by alanine aminotransferase or aspartate aminotransferase more than 5-10 times of the upper limit of normal, alkaline phosphatase more than 5-10 times of the upper limit of normal, or total bilirubin more than 2.5-5 times of the upper limit of normal.

\section{Procedures}

A computer-generated randomization sequence with a block of six was created by the statistician who was not involved in the study. All eligible patients received tenofovir disoproxil fumarate $300 \mathrm{mg}$ plus lamivudine (3TC) $300 \mathrm{mg}$ once daily. Patients were randomly assigned either to undergo $C Y P 2 B 6$ screening study before ART initiation in the $C Y P 2 B 6$-guided group or to promptly initiate ART regardless of $C Y P 2 B 6$ results in the controlled group. If $C Y P 2 B 6 * 6 / * 6$ was found in $C Y P 2 B 6^{*} 6 / * 6$, the patients would be initiated on a low dose of $400 \mathrm{mg}$ of EFV (two tablets of $200 \mathrm{mg}$ ). The others would be initiated on a standard dose of $600 \mathrm{mg}$ of EFV (one tablet of $600 \mathrm{mg}$ ). The patients and doctors in the control group did not know their CYP2B6 genotype and the EFV concentration in plasma.

Clinic visits were scheduled for physical examination, adverse event reporting, biochemistry, hematology, immunology, HIV RNA, and CYP2B6 at week 0. Telephone visits were scheduled at week 1 for adverse event reporting. Physical examination, adverse event reporting, biochemistry, hematology, and EFV plasma concentration were performed at week 4, 12, and 24. CD4 cell count and HIV RNA were added to schedule at week 12 and 24. Plasma HIV RNA was also measured at one reference laboratory with the Abbott m2000 real-time HIV-1 test (lower limit of detection is 40 copies/mL).

\section{Genomic DNA extraction}

Blood samples were collected in EDTA tubes. DNA was isolated using the MagNA Pure automated extraction 
system (Roche Diagnostics, Indianapolis, IN, USA), which uses magnetic-bead technology with a lysis buffer and proteinase K. Nucleic acids bind to the surface of the magnetic glass particles. Cellular debris was removed by several washing steps and the purified nucleic acids were eluted. From the $1 \mathrm{~mL}$ input volume of EDTA-whole blood, $200 \mu \mathrm{L}$ output volume of extracted genomic DNA product was obtained. The quality of genomic DNA was assessed by using Nano Drop ND-1000. Genomic DNA was detected by measuring absorbance at $260 \mathrm{~nm}$. Purity of the sample was evaluated by calculating the optical density (OD) ratio, 260/280 $\mathrm{nm}$. The recommended purified genomic DNA template for this study was $20 \mathrm{ng}$, and the OD ratio greater than 1.7. All DNA was aliquoted and stored at $-20^{\circ} \mathrm{C}$ before analysis.

\section{CYP2B6 genotyping}

All $10 \mathrm{~mL}$ EDTA blood samples were submitted to the laboratory of Pharmacogenomics and Personalized Medicine, Faculty of Medicine Ramathibodi Hospital, for CYP2B6 genotype and EFV plasma concentration level analysis. Predesigned TaqMan assays (Applied Biosystems, Foster City, CA, USA) were used to genotype the predesigned TaqMan assays (Applied Biosystems) and were also used to genotype the CYP2B6c.516G > T (assay ID C_7817765_60), c.64C $>$ T (assay ID C_2818162_20), c.499C $>$ G (assay ID C_2752377_10), c.1375A $>$ G (assay ID C_2741754_10), c.1459C $>$ T (assay ID C_30634242_40), g.3003T $>C$ (assay ID C_2818167_10), and g.21563C $>\mathrm{T}$ (assay ID C__22275631_10). The CYP2B6 c.785A $>\mathrm{G}$ was performed by custom TaqMan assays (Applied Biosystems). The sequences of primers and probes were as follows: CYP2B6 c.785A $>$ G, TGGAGAAGCACCGTGAAACC (forward), TGGAGCAGGTAGGTGTCGAT (reverse), VIC-CCCCCAAGGACCTC-MGB (wild-type), FAMCCCCAGGGACCTC-MGB (mutant).

For single nucleotide polymorphism (SNP) analysis, this SNP was genotyped using allele-specific fluorogenic $5^{\prime}$ nuclease chain reaction assay with predesigned primers and TaqMan MGB probes (TaqMan SNP Genotyping Assay; Applied Biosystems). Sequence-specific forward and reverse primers to amplify the polymorphic sequence of interest used two TaqMan MGB probes: one probe was labeled with VIC dye and detected the allele 1 sequence, and the second probe was labeled with FAM dye and detected the allele 2 sequences. CYP2B6 haplotype determination was interpreted using the Human Cytochrome P450 (CYP) Allele Nomenclature Database (http://www.cypalleles.ki.se/ cyp2b6.htm).

\section{Measurement of EFV plasma concentrations}

Fasting plasma EFV level at 12 hours after dosing was measured using a validated high-performance liquid chromatopraphy assay at 4, 12, and 24 weeks of ART initiation. Briefly, patient plasma samples $(300 \mu \mathrm{L})$ and all calibrations and control samples were heat inactivated in a water bath at $56^{\circ} \mathrm{C}$ for 30 minutes prior to assay. Sample pretreatment involved protein precipitation with acetonitrile $(360 \mu \mathrm{L})$, and followed centrifugation, the sample supernatant was injected into the HPLC machine.

Analysis was performed using an Agilent 1100 HPLC machine with an Omnispher C18 $(150 \times 4.6 \mathrm{~mm} \mathrm{ID/particle}$ size $5 \mu \mathrm{m}$ ) analytical column (Varian, Palo Alto, CA, USA), a Chromquard RP guard column, and a mobile phase consisting of $10 \mathrm{mM} \mathrm{KH}_{2} \mathrm{PO}_{4} \mathrm{pH} 3.1$ acetonitrile $(50: 50, \mathrm{v} / \mathrm{v})$. The retention time for EFV was 5.1 minutes. The peak of this compound was well resolved and free of interference from endogenous compounds in the plasma. The lower limit of quantification of EFV is $0.2 \mathrm{mg} / \mathrm{L}$. The detection limit was defined as a signal-to-noise ratio of 3:1. The calibration standards for plasma samples were linear in the range of 0.2-20 mg/L. Low-, medium-, and high-level QC samples were prepared at $0.4,1.5$, and $10 \mathrm{mg} / \mathrm{L}$, respectively. The intra- and interday precision was within $0.0758 \%$ and $0.0091 \%$, respectively. The assay accuracy was $93 \%-04 \%$.

\section{Study outcomes}

The primary end point was to compare the proportion of patients who had undetectable HIV RNA at 24 weeks after ART initiation among patients who received CYP2B6-guided EFV dose and who did not. Secondary end points were the proportion of EFV adverse neuropsychiatric events and EFV trough concentration associated with $C Y P 2 B 6$. The prevalence of $C Y P 2 B 6$ and effectiveness of performing $C Y P 2 B 6$ screening were also determined.

\section{Statistical analysis}

Results are expressed as percentage for categorical variables, mean and standard deviation (SD) for continuous normally distributed variables, and median and interquartile range (IQR) for continuous nonnormally distributed variables. The primary efficacy end point was analyzed in accordance with the per protocol principle. The secondary end points were analyzed using modified intention-to-treat principle. The modified intention-to-treat analyses were defined for the patients who received at least one dose of EFV and had at least one follow-up. Statistical analyses were performed 
using Stata Statistical Software version 13.0 (Stata Corporation, College Station, TX, USA).

\section{Results}

A total of $26 \mathrm{HIV}$-infected patients were recruited. Two patients were excluded from the study; one had active pulmonary tuberculosis and the other refused to start ART. Finally, 24 patients were randomized and initiated ART. In all, 12 patients were first assigned to undergo $C Y P 2 B 6$ screening to decide EFV dose and another 12 patients were initiated on ART promptly at the first visit. Nine (75\%) patients in CYP2B6 guided group and eight (66.7\%) patients in control group completed the follow-up visit at week 24. The study profile is shown in Figure 1.

Baseline characteristics are listed in Table 1. Overall, $66.7 \%$ patients were men with a median (IQR) age of 37 (25-45) years. Of all, 45.8\% had heterosexual risk for HIV acquisition, $37.5 \%$ had homosexual risk, and 16.7\% were injected drug users. Eight (33.3\%) patients had another underlying medical condition. Seventy percent had asymptomatic HIV infection (CDC category A), 8.3\% had symptomatic HIV infection (CDC category B), and $21.7 \%$ had AIDS-defining illness (CDC category C). The common AIDS-defining illnesses were Pneumocystis jerovecii pneumonia (12.5\%), followed by tuberculosis (8.3\%) and cervical cancer $(8.3 \%)$. Median (IQR) CD4 cell count at ART initiation was 252 (108-396) cells/mL and median (IQR) plasma HIV RNA in $\log _{10}$ was 4.66 (3.84-5.48) copies/mL.

There was no statistically significant difference in baseline characteristics among the two groups. The median age was 36.5 years in CYP2B6-guided group and 38.5 years in the control group. There were more men and more cases of homosexual contact in CYP2B6-guided group. Median alanine aminotransferase was higher in CYP2B6-guided group than in control group (39.5 versus $30.5 \mathrm{U} / \mathrm{L}$ ).

Baseline characteristics of polymorphism in $C Y P 2 B 6$ are listed in Table 2. Of these, $12(50 \%)$ patients were extensive metabolizers $(* 1 / * 1, * 1 / * 2$, and $* 1 / * 4), 10(41.7 \%)$ patients were intermediate metabolizers $(* 1 / * 6$ and $* 4 / * 6)$, and only two patients $(8.3 \%)$ were poor metabolizers $(* 6 / * 6)$. There were more patients with $C Y P 2 B 6 * 1 / * 1$ in $C Y P 2 B 6$-guided group and more patients with $C Y P 2 B 6 * 1 / * 6$ in control

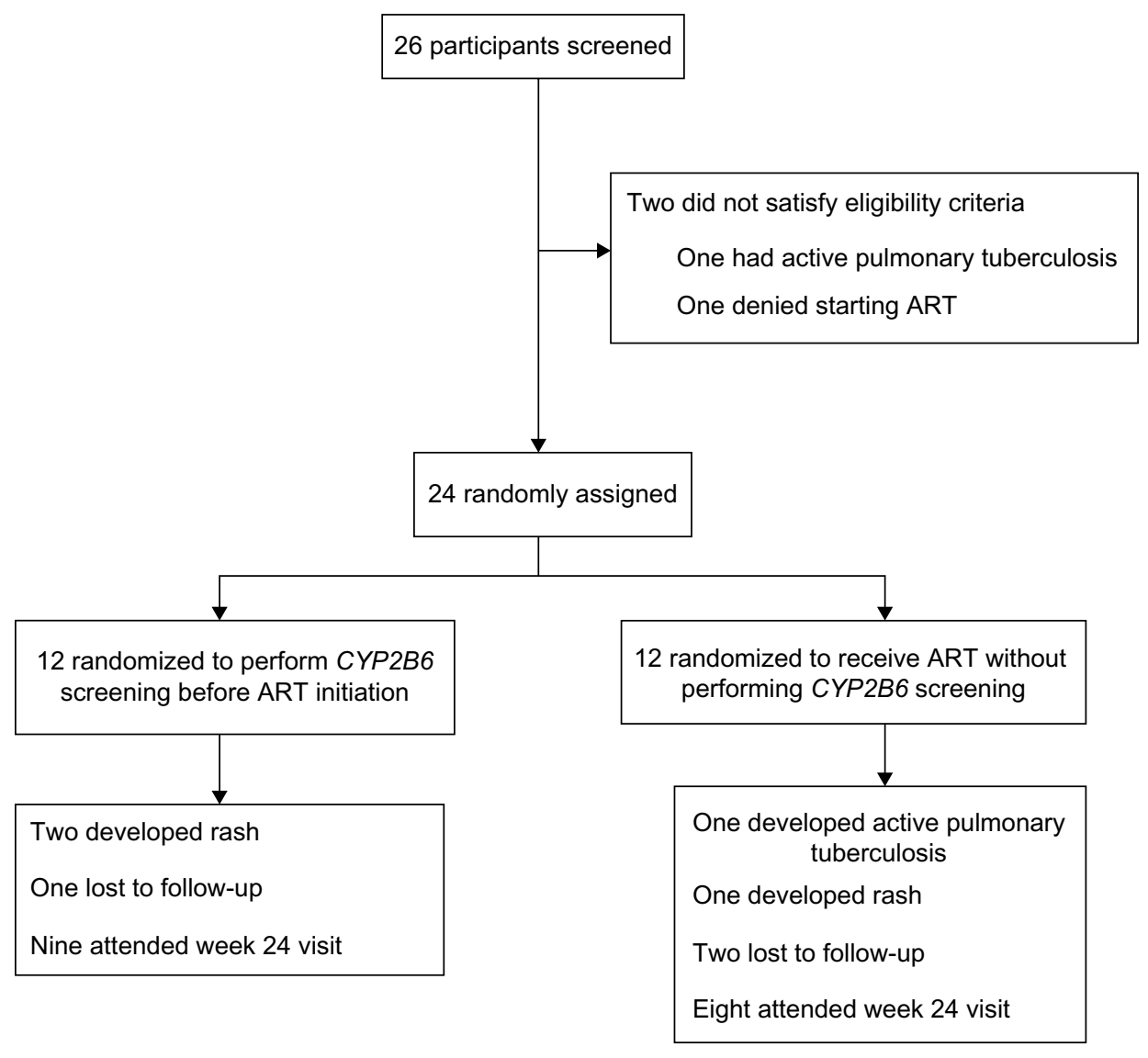

Figure I Study flow diagram.

Abbreviations: ART, antiretroviral therapy; CYP2B6, cytochrome P450 2 B6. 
Table I Baseline characteristics of $24 \mathrm{HIV}$-infected patients

\begin{tabular}{|c|c|c|}
\hline Characteristics & $\begin{array}{l}\text { CYP2B6-guided } \\
\text { group }(\mathrm{N}=12)\end{array}$ & $\begin{array}{l}\text { Control group } \\
(\mathrm{N}=12)\end{array}$ \\
\hline Men, n (\%) & $10(83.3)$ & $6(50.0)$ \\
\hline Median (IQR) age, years & $36.5(26.5-44.3)$ & $38.5(23.8-50.5)$ \\
\hline Median (IQR) body & $22.0(20.9-24.5)$ & $20.5(16.0-22.4)$ \\
\hline \multicolumn{3}{|l|}{ mass index, $\mathrm{kg} / \mathrm{m}^{2}$} \\
\hline \multicolumn{3}{|l|}{ Route of HIV acquisition, n (\%) } \\
\hline Heterosexual contact & $5(4 \mid .7)$ & $6(50.0)$ \\
\hline Homosexual contact & $6(50.0)$ & $3(25.0)$ \\
\hline Injecting drug user & I (8.3) & $3(25.0)$ \\
\hline \multicolumn{3}{|l|}{ CDC category, n (\%) } \\
\hline$A$ & $9(75.0)$ & $8(66.7)$ \\
\hline B & I (8.3) & I (8.3) \\
\hline C & $2(16.7)$ & $3(25.0)$ \\
\hline Median (IQR) plasma & $4.63(4.45-5.47)$ & $4.82(3.94-5.65)$ \\
\hline \multicolumn{3}{|l|}{ HIV RNA, $\log _{10}$ copies $/ \mathrm{mL}^{\mathrm{a}}$} \\
\hline Median (IQR) CD4 & $223(53-326)$ & $274(10|-3| 4)$ \\
\hline \multicolumn{3}{|l|}{ cell count, cells $/ \mathrm{mL}$} \\
\hline Positive HBsAg, n (\%) & $2(16.7)$ & $\mathrm{I}(8.3)$ \\
\hline Positive anti-HCV, n (\%) & I (8.3) & 0 \\
\hline $\begin{array}{l}\text { Median (IQR) alanine } \\
\text { aminotransferase, } \mathrm{U} / \mathrm{L}\end{array}$ & $39.5(27.3-71.5)$ & $30.5(23.0-43.0)$ \\
\hline Median (IQR) creatinine, $\mathrm{mg} / \mathrm{dL}$ & $0.94(0.85-1.05)$ & $0.83(0.69-0.92)$ \\
\hline
\end{tabular}

Notes: aPlasma HIV RNA was performed in six patients in the CYP2B6-guided group and in seven patients in the control group.

Abbreviations: CYP2B6, cytochrome P450 2B6; SD, standard deviation; IQR, interquartile range; $\mathrm{HbsAg}$, surface antigen of the hepatitis $B$ virus; $\mathrm{HCV}$, hepatitis $\mathrm{C}$ virus; CDC, Center for Disease Control and Prevention.

group. The polymorphism $C Y P 2 B 6 * 6 / * 6$ was found in only one patient in each group (8.3\%). Thus, one patient in CYP2B6-guided group was assigned to receive EFV $400 \mathrm{mg}$ with therapeutic drug monitoring and the other one in control group received EFV $600 \mathrm{mg}$ without dose adjustments.

The primary outcome is listed in Table 3. Of all, 17 patients were able to achieve undetectable HIV RNA at week 24. The overall EFV trough concentrations during the follow-up were similar in both groups. The mean (SD) EFV levels were 1.675 (0.963), 1.445 (0.778), and $1.899(0.808) \mu \mathrm{g} /$ $\mathrm{mL}$ in week 4,12 , and 24 , respectively. The CYP2B6 *6/*6

Table 2 Polymorphism CYP2B6 in 24 HIV-infected patients

\begin{tabular}{lll}
\hline $\begin{array}{l}\text { Polymorphism in } \\
\text { CYP2B6, } \mathbf{n}(\%)\end{array}$ & $\begin{array}{l}\text { CYP2B6-guided } \\
\text { group }(\mathbf{N}=\mid \mathbf{2})\end{array}$ & $\begin{array}{l}\text { Control } \\
\text { group }(\mathbf{N}=\mathbf{I})\end{array}$ \\
\hline$* 1 / * 1$ & $3(25.0)$ & $6(50.0)$ \\
$* 1 / * 2$ & 0 & $\mathrm{I}(8.3)$ \\
$* 1 / * 4$ & $2(16.7)$ & 0 \\
$* 1 / * 6$ & $6(50.0)$ & $3(25.0)$ \\
$* 4 / * 6$ & 0 & $\mathrm{I}(8.3)$ \\
$* 6 / * 6$ & $\mathrm{I}(8.3)$ & $\mathrm{I}(8.3)$ \\
\hline
\end{tabular}

Notes: CYP2B6 haplotype determination was interpreted using the Human Cytochrome P450 (CYP) Allele Nomenclature Database (http://www.cypalleles.ki.sel cyp2b6.htm). All SNPs were included for CYP2B6 haplotype interpretation.

Abbreviations: CYP2B6, cytochrome P450 2B6; SNP, single nucleotide polymorphism.
Table 3 Primary and secondary outcomes in 17 HIV-infected patients

\begin{tabular}{|c|c|c|c|}
\hline Outcomes & $\begin{array}{l}\text { CYP2B6-guided } \\
\text { group }(\mathrm{N}=9)\end{array}$ & $\begin{array}{l}\text { Control } \\
\text { group }(\mathrm{N}=8)\end{array}$ & $P$-value \\
\hline \multicolumn{4}{|l|}{ Primary outcome, n (\%) } \\
\hline $\begin{array}{l}\text { HIV RNA }<40 \text { copies } / \mathrm{mL} \\
\text { at week } 24\end{array}$ & $9(100)$ & $8(100)$ & 1.000 \\
\hline \multicolumn{4}{|l|}{ Secondary outcome } \\
\hline \multicolumn{4}{|c|}{ Mean (SD) efavirenz level, $\mu \mathrm{g} / \mathrm{mL}$} \\
\hline Week 4 & $\mathrm{I} .449(0.904)$ & $1.900(1.013)$ & 0.824 \\
\hline Week 12 & I.36I (0.447) & $1.542(1.024)$ & 0.254 \\
\hline Week 24 & $\mathrm{I} .890(0.76 \mathrm{I})$ & $\mathrm{I} .823(0.845)$ & 0.837 \\
\hline \multicolumn{4}{|l|}{ Adverse events, $n(\%)^{a}$} \\
\hline Overall & II (9I.7) & II (9I.7) & \\
\hline \multicolumn{4}{|l|}{ Neuropsychiatric events } \\
\hline Dizziness & $8(66.7)$ & $10(83.3)$ & \\
\hline Scary dream & 0 & I (8.3) & \\
\hline Vivid dream & $2(16.7)$ & 0 & \\
\hline Difficult to concentration & I (8.3) & 0 & \\
\hline Confusion & I (8.3) & 0 & \\
\hline Nausea & $2(16.7)$ & I (8.3) & \\
\hline Vomiting & $2(16.7)$ & I (8.3) & \\
\hline Rash & $2(16.7)$ & I (8.3) & \\
\hline Hepatitis $^{\mathrm{b}}$ & $\mathrm{I}(8.3)$ & 0 & \\
\hline
\end{tabular}

Notes: ${ }^{a}$ Adverse events might occur (more than one event in some patients); belevation of alanine aminotransferase more than three times the normal upper limit. Abbreviations: CYP2B6, cytochrome P450 2B6; SD, standard deviation.

patient who received lower dose EFV had lower EFV level than those who received normal dose, 2.093 versus 4.356, 1.880 versus 3.763 , and 1.776 versus $3.473 \mu \mathrm{g} / \mathrm{mL}$ at week 4,12 , and 24, respectively. Mean EFV level was lower in the patient who received low-dose EFV compared to those who received normal dose, 1.916 versus $3.915 \mu \mathrm{g} / \mathrm{mL}$, respectively, $(P<0.001$; Figure 2).

Overall adverse events were found in $22(91.7 \%)$ patients and occurred more than once in some patients. The most severe adverse event that had influenced patients' decision to change or discontinue EFV was rash (two in CYP2B6-guided group and one in control group). However, rash was minor, not Steven-Johnson syndrome/toxic epidermal necrosis. Of these, $70 \%$ of the patients had neuropsychiatric problems, especially dizziness. The duration of dizziness that they experienced was 12.3 days in CYP2B6-guided group and 15.4 days in control group $(P=0.836)$. There was no adverse event in the patients who received the adjusted EFV dose.

\section{Discussion}

Our study is the first prospective randomized controlled trial of using CYP2B6-guided EFV dose for initiation. In this study, we identified a CYP2B6 allele in 24 Thai patients, and we showed that extensive and intermediate metabolizers were approximately $92 \%$. In addition, poor metabolizers 


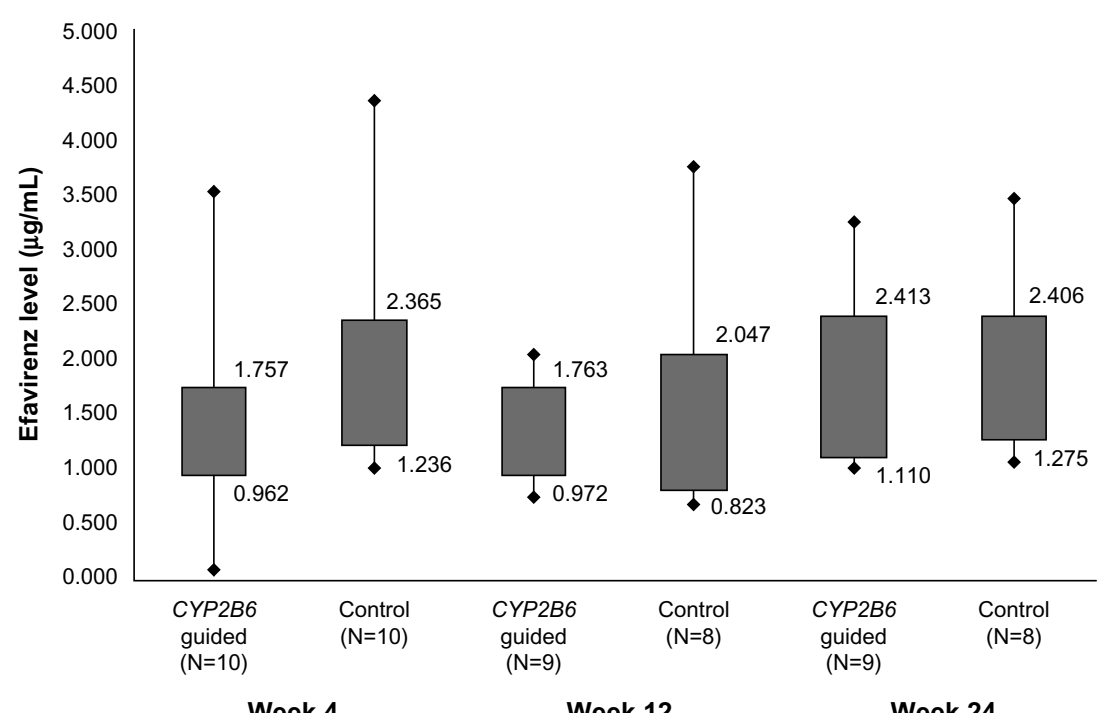

Week 4

Week 12

Week 24

Figure 2 Efavirenz concentrations in plasma at 4, 12, and 24 weeks.

Note: The boxes represent interquartile range and lines represent minimum and maximum value. Abbreviation: CYP2B6, cytochrome P450 2B6.

$($ CYP $2 B 6 * 6 / * 6)$ were $8.3 \%$, and CYP $2 B 6 * 6 / * 6$ carriers had high plasma EFV levels while receiving the standard dose. HIV RNA was undetectable at 24 weeks in all patients who completed follow-up.

Now, the recommended range of plasma EFV concentration at 12 hours after dosing is proposed to be $1-4 \mu \mathrm{g} / \mathrm{mL}^{5,22-}$ ${ }^{24}$ The subtherapeutic EFV plasma concentrations can lead to the development of viral resistance against EFV. ${ }^{25}$ This is because EFV has a low genetic barrier to viral drug resistance, resulting in only a single mutation, most frequently K103N. 5,23,24 Treatment failure has been found to be more frequent in patients with low EFV trough level compared to those with a high level $(>1.1 \mu \mathrm{g} / \mathrm{mL}) .{ }^{26}$ During follow-up, we also found that five patients had EFV concentration less than $1 \mu \mathrm{g} / \mathrm{mL}$ (range: $0.691-0.971 \mu \mathrm{g} / \mathrm{mL}$ ). Three patients had subtherapeutic level at week 12 and two patients at week 4 and 12. However, all patients had normal requirement for plasma EFV concentration at week 24. Seventeen patients were able to achieve undetectable HIV RNA in their plasma at 24 weeks after ART initiation.

The patient with $C Y P 2 B 6^{*} 6 / * 6$ in this study had a normal requirement concentration while receiving $400 \mathrm{mg}$ of EFV and was also able to achieve the undetectable HIV RNA levels. As in the previous study, ${ }^{19}$ the plasma concentrations of EFV were therapeutically adequate in all the treated $* 6 / * 6$ and $* 6 / * 26$ carriers at the $400 \mathrm{mg}$ dose.

The higher EFV concentration increased incidence of EFV-associated neuropsychological toxicity, ${ }^{5,18,20}$ especially CYP $2 B 6 * 6 / * 6$. In our study, we found that almost all patients had dizziness symptom regardless of the mutation of CYP2B6. Other polymorphisms might also have an influence on EFV concentration, eg, CYP2B6T18492C. . $27,28^{28}$

Pharmacogenetics and pharmacokinetics combined with therapeutic drug monitoring should be used to guide EFV dosages. ${ }^{29,30}$ Thus, CYP2B6 genotyping should be introduced in routine clinical practice because it would help the patients to avoid or decrease the adverse neuropsychiatric events after the initiation of EFV-based antiretroviral regimen. In this study, one patient who had $C Y P 2 B 6 * 6 / * 6$ and adjusted EFV dose did not have any adverse events. Furthermore, there was a new concept from the ENCORE1 study. ${ }^{31}$ It showed that a reduced dose of $400 \mathrm{mg}$ EFV is noninferior to the standard dose of $600 \mathrm{mg}$ in ART-naïve adults with HIV-1 infection. Adverse events related to the study drug were more frequent with $600 \mathrm{mg}$ EFV than with $400 \mathrm{mg}$. Nevertheless, body weight was a factor because the plasma EFV concentrations persistently decreased at $0.9 \mathrm{mg} / \mathrm{L}$ for every $10 \mathrm{~kg}$ of increased body weight. ${ }^{28}$

There were a few limitations in this study. First, the number of patients was too small to generalize the results. Second, we found low prevalence of $C Y P 2 B 6 * 6 / * 6$ in this study, and only one patient received EFV dosage adjustment. Third, we studied only in Thais, which may not be representative of the general information in other ethnic groups. Last, laboratory costs, eg, HIV RNA, CYP2B6 genotype, and EFV concentration (US\$50US\$60 per test), were quite expensive compared to general national income and government health insurance. It should therefore be considered individually for every person. 
In conclusion, a trend toward association of the $C Y P 2 B 6$ polymorphism and plasma EFV concentrations in this study was demonstrated. Reduced EFV dose should be considered in $C Y P 2 B 6 * 6 /{ }^{*} 6$ carrier so as to help the patient not to experience adverse neuropsychological events. The patients could achieve the therapeutic EFV level and undetectable HIV RNA after initiation of ART. Pharmacogenetics and therapeutic drug monitoring might play an important role in patients to help them avoid severe adverse events. Screening CYP2B6 in HIV-infected Thai patients should be considered individually because of the low prevalence of this mutation and the accessibility of this test to the general public.

\section{Acknowledgments}

This study was supported by research grant from the Faculty of Medicine Ramathibodi Hospital, Mahidol University and New Researchers Grant (MRG 5480136), The Mahidol University (MU)/the Thailand Research Fund and Office of the Higher Education Commission, and the Thailand Research Fund (TRF). The authors are also grateful to all patients who contributed to the study.

\section{Disclosure}

The authors report no conflicts of interest in this work.

\section{References}

1. World Health Organization. Consolidated guidelines on the use of antiretroviral drugs for treating and preventing HIV infection. Available from: http://www.who.int/hiv/pub/guidelines/arv2013/en/. Accessed August 17, 2015.

2. European AIDS Clinical Society (EACS) Guidelines. European AIDS Clinical Society (EACS). Available from: http://eacsociety. org/Portals/0/Guidelines_Online_131014.pdf. Accessed August 17, 2015 .

3. Sungkanuparph S, Techasathit W, Utaipiboon C, et al. Thai national guidelines for antiretroviral therapy in HIV-1 infected adults and adolescents 2010. Asian Biomed. 2010;4(4):515-528.

4. Shah MD, Balderson K. A manic episode associated with efavirenz therapy for HIV infection. AIDS. 2003;17(11):1713-1714.

5. Marzolini C, Telenti A, Decosterd LA, et al. Efavirenz plasma levels can predict treatment failure and central nervous system side effects in HIV-1-infected patients. AIDS. 2001;15(1):71-75.

6. Sanchez-Conde M, Palacios R, Sanz J, et al. Efficacy and safety of a once daily regimen with efavirenz, lamivudine, and didanosine, with and without food, as initial therapy for HIV Infection: the ELADI study. AIDS Res Hum Retroviruses. 2007;23(10):1237-1241.

7. Rakhmanina NY, van den Anker JN. Efavirenz in the therapy of HIV infection. Expert Opin Drug Metab Toxicol. 2010;6(1):95-103.

8. Gutierrez F, Navarro A, Padilla S, et al. Prediction of neuropsychiatric adverse events associated with long-term efavirenz therapy, using plasma drug level monitoring. Clin Infect Dis. 2005;41(11): 1648-1653.

9. Hasse B, Gunthard HF, Bleiber G, Krause M. Efavirenz intoxication due to slow hepatic metabolism. Clin Infect Dis. 2005;40(3):e22-e23.
10. Djabarouti S, Breilh D, Pellegrin I, et al. Intracellular and plasma efavirenz concentrations in HIV-infected patients switching from successful protease inhibitor-based highly active antiretroviral therapy (HAART) to efavirenz-based HAART (SUSTIPHAR Study). J Antimicrob Chemother. 2006;58(5):1090-1093.

11. Rodriguez-Novoa S, Barreiro P, Jimenez-Nacher I, Soriano V. Overview of the pharmacogenetics of HIV therapy. Pharmacogenomics J. 2006; 6(4):234-245.

12. Ma JD, Lee KC, Kuo GM. HLA-B*5701 testing to predict abacavir hypersensitivity. PLoS Curr. 2010;2:RRN1203.

13. Haas DW, Gebretsadik T, Mayo G, et al. Associations between CYP2B6 polymorphisms and pharmacokinetics after a single dose of nevirapine or efavirenz in African americans. J Infect Dis. 2009;199(6): $872-880$.

14. Uttayamakul S, Likanonsakul S, Manosuthi W, et al. Effects of CYP2B6 G516T polymorphisms on plasma efavirenz and nevirapine levels when co-administered with rifampicin in HIV/TB co-infected Thai adults. AIDS Res Ther. 2010;7:8.

15. Michaud V, Bar-Magen T, Turgeon J, Flockhart D, Desta Z, Wainberg MA. The dual role of pharmacogenetics in HIV treatment: mutations and polymorphisms regulating antiretroviral drug resistance and disposition. Pharmacol Rev. 2012;64(3):803-833.

16. Haas DW, Ribaudo HJ, Kim RB, et al. Pharmacogenetics of efavirenz and central nervous system side effects: an Adult AIDS Clinical Trials Group study. AIDS. 2004;18(18):2391-2400.

17. Tsuchiya K, Gatanaga H, Tachikawa N, et al. Homozygous CYP2B6*6 (Q172H and K262R) correlates with high plasma efavirenz concentrations in HIV-1 patients treated with standard efavirenzcontaining regimens. Biochem Biophys Res Commun. 2004;319(4): 1322-1326.

18. Manosuthi W, Sukasem C, Lueangniyomkul A, et al. Impact of pharmacogenetic markers of CYP2B6, clinical factors, and drug-drug interaction on efavirenz concentrations in HIV/tuberculosis-coinfected patients. Antimicrob Agents Chemother. 2013;57(2):1019-1024.

19. Gatanaga H, Hayashida T, Tsuchiya K, et al. Successful efavirenz dose reduction in HIV type 1-infected individuals with cytochrome P450 2B6 *6 and *26. Clin Infect Dis. 2007;45(9):1230-1237.

20. Sukasem C, Cressey TR, Prapaithong P, et al. Pharmacogenetic markers of CYP2B6 associated with efavirenz plasma concentrations in HIV-1 infected Thai adults. Br J Clin Pharmacol. 2012;74(6): 1005-1012.

21. Sukasem C, Chamnanphon M, Koomdee N, et al. High plasma efavirenz concentration and CYP2B6 polymorphisms in Thai HIV-1 infections. Drug Metab Pharmacokinet. 2013;28(5):391-397.

22. Manosuthi W, Sungkanuparph S, Tantanathip P, et al. A randomized trial comparing plasma drug concentrations and efficacies between 2 nonnucleoside reverse-transcriptase inhibitor-based regimens in HIV-infected patients receiving rifampicin: the N2R Study. Clin Infect Dis. 2009;48(12):1752-1759.

23. Csajka C, Marzolini C, Fattinger K, et al. Population pharmacokinetics and effects of efavirenz in patients with human immunodeficiency virus infection. Clin Pharmacol Ther. 2003;73(1):20-30.

24. Sanchez A, Cabrera S, Santos D, et al. Population pharmacokinetic/ pharmacogenetic model for optimization of efavirenz therapy in Caucasian HIV-infected patients. Antimicrob Agents Chemother. 2011;55(11):5314-5324.

25. Pretorius E, Klinker H, Rosenkranz B. The role of therapeutic drug monitoring in the management of patients with human immunodeficiency virus infection. Ther Drug Monit. 2011;33(3):265-274.

26. Pfister M, Labbe L, Hammer SM, et al. Population pharmacokinetics and pharmacodynamics of efavirenz, nelfinavir, and indinavir: adult AIDS Clinical Trial Group Study 398. Antimicrob Agents Chemother. 2003;47(1):130-137.

27. Sukasem C, Manosuthi W, Koomdee N, et al. Low level of efavirenz in HIV-1-infected Thai adults is associated with the CYP2B6 polymorphism. Infection. 2014;42(3):469-474. 
28. Manosuthi W, Sukasem C, Thongyen S, Nilkamhang S, Manosuthi S, Sungkanuparph S. CYP2B6 18492T $\rightarrow$ C polymorphism compromises efavirenz concentration in coinfected HIV and tuberculosis patients carrying CYP2B6 haplotype *1/*1. Antimicrob Agents Chemother. 2014;58(4):2268-2273.

29. Clevenbergh P, Mouly S, Sellier P, et al. Improving HIV infection management using antiretroviral plasma drug levels monitoring: a clinician's point of view. Curr HIV Res. 2004;2:309-321.
30. Fabbiani M, Bracciale L, Ragazzoni E, et al. Relationship between antiretroviral plasma concentration and emergence of HIV-1 resistance mutations at treatment failure. Infection. 2011;39(6):563-569.

31. Puls R, Amin J, Losso M, et al. Efficacy of $400 \mathrm{mg}$ efavirenz versus standard $600 \mathrm{mg}$ dose in HIV-infected, antiretroviral-naive adults (ENCORE1): a randomised, double-blind, placebo-controlled, noninferiority trial. Lancet. 2014;383(9927):1474-1482.

\section{Publish your work in this journal}

Pharmacogenomics and Personalized Medicine is an international, peerreviewed, open access journal characterizing the influence of genotype on pharmacology leading to the development of personalized treatment programs and individualized drug selection for improved safety, efficacy and sustainability. This journal is indexed on the American Chemical
Society's Chemical Abstracts Service (CAS). The manuscript management system is completely online and includes a very quick and fair peer-review system, which is all easy to use. Visit http://www.dovepress. com/testimonials.php to read real quotes from published authors.

Submit your manuscript here: http://www.dovepress.com/pharmacogenomics-and-personalized-medicine-journal 